\title{
Developing a community HCV service: project ITTREAT (integrated community-based test - stage - TREAT) service for people who inject drugs
}

\author{
Ahmed Hashim ${ }^{1,2}$, Margaret O'Sullivan ${ }^{2,3}$, Hugh Williams ${ }^{3,4}$ and Sumita Verma ${ }^{1,2}$ \\ ${ }^{1}$ Department of Medicine, Brighton and Sussex Medical School, Brighton, UK \\ ${ }^{2}$ Department of Gastroenterology and Hepatology, Brighton and Sussex University Hospital, Brighton, UK \\ ${ }^{3}$ Pavilions Drug \& Alcohol Services, Richmond House, Brighton, UK \\ ${ }^{4}$ Surrey and Borders Partnership NHS foundation trust
}

\begin{abstract}
Background and aims: Majority of the individuals with hepatitis $\mathrm{C}$ virus (HCV) infection in England are people who inject drugs, a vulnerable and disenfranchised cohort with poor engagement with secondary care. Our aim is to describe our experiences in setting up a successful nurse led HCV service at a substance misuse service (SMS). Methods: We justify the need for a community HCV service and review the different community based models. Our experiences in engaging with stakeholders, obtaining funding, service set up, challenges faced and key recommendations are discussed. Finally, a summary of interim clinical outcomes is presented. Results: A successful community based "one-stop" nurse led HCV service was set up in Dec 2013 at a large SMS. It provides all aspects of care (blood borne virus screening, non-invasive assessment of hepatic fibrosis, Hepatology input, $\mathrm{HCV}$ treatment, peer mentor, social and psychiatrist support, and opiod substitution) at one site. Interim clinical data indicate high service uptake with HCV treatment outcomes comparable to secondary care. Conclusions: The advent of direct acting antivirals provides a unique opportunity for HCV elimination in England by 2030. Our "one-stop" integrated and multidisciplinary community HCV model suggests that HCV care can be successfully delivered outside of a hospital setting and warrants national adoption.
\end{abstract}

Key words: CLD; community model; HCV; hepatitis C; PWID

Received 3 April 2017; revised 5 September 2017; accepted 8 October 2017; first published online 4 December 2017

\section{Introduction}

Liver disease is the third most common cause of premature death in the United Kingdom (Williams et al., 2014). Chronic HCV infection remains a major national health burden [Public Health England (PHE), 2017c] with an estimated 160000 individuals infected (Harris et al., 2012). Globally,

Correspondence to: Dr Sumita Verma, MBBS, MD, FRCP, Reader in Medicine, Brighton and Sussex Medical School Honorary Consultant Hepatology, Brighton and Sussex University, Hospital Falmer Brighton, BN1 9PX, UK, Email: s.verma@bsms.ac.uk deaths from viral hepatitis (1.4 million/year) have now surpassed that of HIV (1.3 million/year), malaria (1.2 million/year) and tuberculosis (0.5 million/year) (Global Burden of Disease and WHO/UNAIDS Estimates, 2015). This mandated the first ever WHO Global Health Sector Strategy (GHSS) in May 2016, which aims for elimination of viral hepatitis by 2030 (WHO, 2016). The vision statement of PHE Hepatitis C report is in line with the WHO GHSS (PHE, 2017c).

Injecting drug use is responsible for $90 \%$ of all HCV infections in England (PHE, 2017c), with $52 \%$ of people who inject drugs (PWID) having a positive HCV serology (PHE, 2017a; 2017b).

(C) Cambridge University Press 2017 
PHE estimates that about $50 \%$ of individuals with HCV may have already been diagnosed (PHE, 2017c); however, only 53\% PWID sampled are aware of their HCV antibody positivity status (UAMS, 2017).

Due to the advent of direct acting antivirals (DAAs), there has been a paradigm shift in the management of chronic HCV infection. DAAs have sustained virological response (SVR) rates (ie, cure) in the high $90 \%$ despite shorter durations of treatment (8-12 weeks), and are effective orally (Feld et al., 2014; 2015; Kowdley et al., 2014; Bell et al., 2016). In England, from June 2015 to April 2016, 38\% more individuals (7036) accessed treatment (Interim Clinical Commissioning Policy Statement, 2014; Clinical Commissioning Policy Statement, 2015) than mean 2008-2014 levels (PHE, 2017c). This may have contributed to the $8 \%$ reduction in deaths from $\mathrm{HCV}$-related end stage liver disease (ESLD) and hepatocellular cancer (HCC) (PHE, 2017c) and 38\% reduction in liver transplantation (38\%) in 2015 (UK Transplant Registry, 2017). DAA treatment outcomes in PWID are comparable with those in secondary care (Dore et al., 2016).

Despite the discovery of DAAs, however, we still need a three to fivefold increase in $\mathrm{HCV}$ diagnosis and treatment if we are to stem the national HCV burden (Wedemeyer et al., 2014). However, PWID remain a vulnerable cohort with poor engagement with hospital services.

\begin{abstract}
Aims
Our aims are to emphasize the need for community services for PWID with HCV infection and give an overview of the different community models. Secondly, we describe our experiences in setting up a successful nurse led service for screening, stratification and treatment of HCV related liver disease at a substance misuse service (SMS). We highlight the important stages of this process including engaging with stakeholders, obtaining funding and service set up. We also explore the obstacles and challenges faced and summarise our key recommendations. Finally, a brief summary of interim clinical outcomes is presented. Detailed outcome data will not be presented in this manuscript as final data analysis (clinical, qualitative, patient reported and health economic outcomes) will be completed mid-2018 and with the aim to publish in a Hepatology focussed journal.
\end{abstract}

\section{HCV community service development}

\section{Stage 1: Establishing a need}

Economic modelling suggests that prioritising $\mathrm{HCV}$ treatment in PWID with a $\leqslant 40 \% \mathrm{HCV}$ seroprevalence and mild to moderate liver disease [in combination with opioid substitution therapy (OST)/needle and syringe programmes] is more cost-effective than treating other patient groups because of the additional benefit of avoiding onwards transmission also known as 'treatment as prevention' (Martin et al., 2013; 2016).

An earlier study from Nottingham, however, showed that overall only $49 \%$ of individuals with a positive HCV serology were referred to a specialist, $27 \%$ attended and $10 \%$ were treated (Irving et al., 2006). A re-audit about 10 years later showed improvement (80\% referred, $70 \%$ attended and $38 \%$ commenced treatment) though clearly there remained scope for improvement (Howes et al., 2016). Barriers to HCV treatment remain at all levels of care (patient, provider and national) (see Figure 1). These include the complex nature of HCV treatment (until recently), inability of health care providers to appreciate the complex needs of vulnerable PWID, perceived stigmatisation and reluctance to treat those actively engaged in alcohol and substance misuse (Irving et al., 2006; Marufu et al., 2012; Dillon et al., 2016).

Locally and as reported by others (Mehta et al., 2008; Lewis et al., 2016) we have been cognisant of the poor uptake of HCV services by PWID.

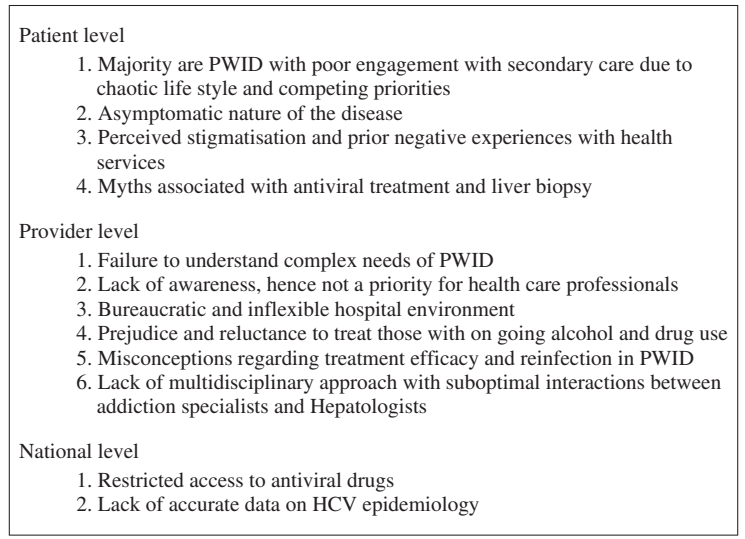

Figure 1 Barriers to care in individuals with hepatitis C virus infection

Primary Health Care Research \& Development 2018; 19: 110-120 
In 2011 we appointed a hepatitis nurse at the largest SMS in Brighton to perform blood dry blood spot testing (DBST) for blood borne virus (BBV) screening with onward referral to Hepatology services. Over a six-month period, of those identified with a positive BBV screen $(n=73), 14$ $(19.1 \%)$ were known to Hepatology services (two previously treated). Of the 40 individuals suitable for antiviral treatment, only two (5\%) engaged with secondary care ( $42 \%$ declined a referral and $37 \%$ disengagement with SMS). No individual was eventually treated (Marufu et al., 2012). Poor uptake of HCV treatment may be contributing to Brighton and Hove having the highest hospital admission/100 000 population with HCV-related ESLD and HCC (4.8, 95\% CI 3.4-6.5), and highest mortality in those aged $<75$ years from $\mathrm{HCV}$ related ESLD and HCC (1.39, 95\% CI 0.70-2.49) in the south east (PHE fingertips).

These data indicates the value of developing innovative community HCV services. Such a novel strategy would represent patient-centred care with earlier diagnosis and treatment, prevention of onwards-viral transmission and potential for reduction in health inequalities. A community-based model with linkage to care is in line with the recently commissioned National Liver Report that advocates screening and treatment for chronic liver disease in the community (Williams et al., 2014).

NHS targets are to treat 10000 individuals with HCV infection in 2016, increasing to 15000/year in 2020 (PHE HCV in England report, 2017). If achieved, statistical modelling predicts that around 2620 people would be living with HCVrelated cirrhosis or HCC (a $81 \%$ reduction) in England by 2030 (Harris et al., 2016) as mandated by the WHO (2016). This is, however, unlikely to be achieved without engaging PWID.

\section{Overview of HCV community models of care}

The model of specialist hepatitis nurses working in SMS/drug and alcohol services has been implemented before, though care has been fragmented, with BBV screening at SMS followed by referral to secondary care (Marufu et al., 2012); even if nurseled treatment has been provided at SMS it is often delivered via out-reach intermittent clinics (Selvapatt et al., 2016) and does not always include assessment of hepatic fibrosis (Grebely et al., 2016). In other models, homeless individuals attending addiction centres underwent review by a consultant hepatologist and a hepatitis nurse but again only on an intermittent (monthly) basis (Wilkinson et al., 2009). Directly observed therapy (DOT) with pegylated interferon and ribavirin (RBV) has also been incorporated into opioid substitution clinics (Bonkovsky et al., 2008). Nonetheless, these DOT models are limited to small randomised-controlled trials and involve close collaboration with secondary and tertiary services - not always feasible in a community setting (Bruggmann and Litwin, 2013).

Group or peer-based treatment has also been trialled, in which an experienced peer co leads the treatment along with a medical provider. This has led to successful treatment outcomes in various settings but relies on pre-treatment engagement (Sylvestre and Clements, 2007). In addition, this model is dependent on excellent group dynamics and effective communication between the peers (Bruggmann and Litwin, 2013).

In the GP based model, a GP with additional HCV training offers treatment to PWIDs alongside OST (Seidenberg et al., 2013). While this model is simple, provision of addiction and HCV treatment by a single GP is demanding and requires great commitment, effort and training of the primary care provider (Seidenberg et al., 2013). Other primary care strategies employed a specialist nurse working in general practices (Jack et al., 2009), but many PWIDs do not engage with their GPs. The Australians, however, have managed to treat $>20000$ individuals with HCV infection during March-June 2016 (previously 20003000 patients treated per/year). Multiple factors contributed to this phenomenal success including prescribing by GPs (Kirby Institute, 2016). In a recent on-going study in South West England, patients in 46 general practices are being randomised to receive either standard care or a complex intervention comprising educational training, posters and leaflets display, the aim being to raise awareness and encourage opportunistic testing through risk prediction algorithms (Roberts et al., 2016).

Other established community HCV programmes such as the American ECHO (The Extension for Community Healthcare Outcomes) project have also shown great success (Arora et al., 2010). This model links hepatologists with primary care physicians in local communities via telehealth technology. It allows optimal management of $\mathrm{HCV}$ patients through 'knowledge networks', bringing together 
Table 1 Pros and cons of different community-based hepatitis $\mathrm{C}$ virus (HCV) models of care

\begin{tabular}{|c|c|c|}
\hline $\begin{array}{l}\text { Community } \\
\text { model }\end{array}$ & Advantages & Limitations \\
\hline $\begin{array}{l}\text { Models based in } \\
\text { General } \\
\text { Practices. } \\
\text { (Jack et al., 2009; } \\
\text { Seidenberg et al., } \\
\text { 2013) }\end{array}$ & $\begin{array}{l}\text { Easy to establish } \\
\text { and incorporates } \\
\text { HCV and } \\
\text { addiction } \\
\text { treatment }\end{array}$ & $\begin{array}{l}\text { Require extensive } \\
\text { training of GPs }\end{array}$ \\
\hline $\begin{array}{l}\text { Directly observed } \\
\text { treatment in } \\
\text { substance } \\
\text { misuse services } \\
\text { (Bonkovsky et al., } \\
\text { 2008) }\end{array}$ & $\begin{array}{l}\text { Established } \\
\text { evidence of } \\
\text { enhanced } \\
\text { adherence }\end{array}$ & $\begin{array}{l}\text { Only small } \\
\text { numbers can be } \\
\text { achieved and } \\
\text { often combined } \\
\text { with secondary } \\
\text { and tertiary } \\
\text { referrals }\end{array}$ \\
\hline $\begin{array}{l}\text { Peer/group-based } \\
\text { treatment } \\
\text { (Sylvestre \& } \\
\text { Clements, 2007) }\end{array}$ & $\begin{array}{l}\text { Potentially } \\
\text { improves } \\
\text { compliance and } \\
\text { enhances patient } \\
\text { motivation }\end{array}$ & $\begin{array}{l}\text { Relies on positive } \\
\text { pre-treatment } \\
\text { engagement and } \\
\text { group dynamics }\end{array}$ \\
\hline $\begin{array}{l}\text { Hepatitis } \\
\text { specialist nurse } \\
\text { in addiction units } \\
\text { (Wilkinson et al., } \\
\text { 2009; Selvapatt } \\
\text { et al., 2016) }\end{array}$ & $\begin{array}{l}\text { Offers specialist } \\
\text { input with ability } \\
\text { to screen and } \\
\text { treat large } \\
\text { numbers of } \\
\text { patients }\end{array}$ & $\begin{array}{l}\text { Lack of an } \\
\text { integrated and } \\
\text { multidisciplinary } \\
\text { approach } \\
\text { including non- } \\
\text { invasive } \\
\text { assessment of } \\
\text { hepatic fibrosis }\end{array}$ \\
\hline $\begin{array}{l}\text { Extension for } \\
\text { Community } \\
\text { Healthcare } \\
\text { Outcomes } \\
\text { (ECHO) model } \\
\text { (Arora et al., } \\
\text { 2010; Beste et al., } \\
\text { 2016) }\end{array}$ & $\begin{array}{l}\text { Widely accepted } \\
\text { and validated }\end{array}$ & $\begin{array}{l}\text { Requires frequent } \\
\text { networking } \\
\text { between GPs and } \\
\text { hepatologists }\end{array}$ \\
\hline
\end{tabular}

expert interdisciplinary specialists from the hospital and multiple community-based primary care practitioners (Arora et al., 2010). Similar outcomes have also been shown in the veteran affairs - ECHO programme (Beste et al., 2016). Other innovative strategies include the French mobile hepatitis team (Remy et al., 2016). Table 1 summarises the pros and cons of the different community HCV models.

Stage 2: Obtaining funding and assembling team Having identified a clear unmet need to link PWID into care by developing a community HCV service model, we then engaged with various stakeholders [SMS, psychiatrists, patient groups

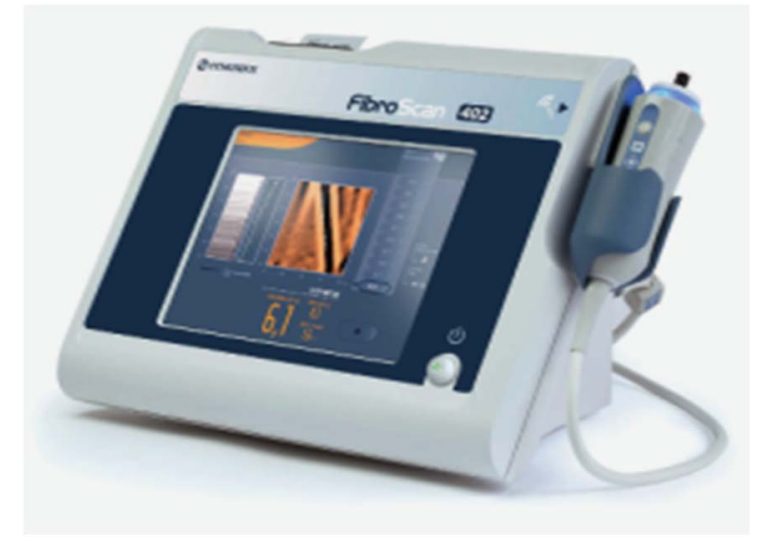

Figure 2 Portable FibroScan ${ }^{\circledR} 402$ device

(Hepatitis C Trust, British Liver Trust), Brighton and Hove Commissioners, and Pharma].

Our aim was to set up a unique 'one-stop' HCV community clinic that provided all components of care (BBV screening, stratification of hepatic fibrosis, nurse-led HCV treatment under hepatologist supervision, hepatitis B vaccination, OST and social and psychiatric input) at one site. In view of the complex needs of PWID our philosophy was that an integrated and multidisciplinary model based at a SMS had the best chance of success. We selected this model rather than one based in primary care due to:

- Our prior established links with the SMS enabling us to engage PWID in an environment they were comfortable in.

- A recent meta analysis and systematic qualitative review suggesting that integrating $\mathrm{HCV}$ treatment and addiction services enhances HCV treatment adherence amongst PWID (Dimova et al., 2012; Rich et al., 2016).

- A historical reluctance by GPs in England to be involved in antiviral prescription.

In 2013, we obtained funding for two years (National Gilead Fellowship and Brighton and Hove Commissioners) to set up our community hepatitis C service at the SMS in Brighton (Sussex Partnership Trust). In 2015, additional funding from the same sources extended our work for two years (until December 2017). The funding allowed for appointment of a band 7-community hepatitis nurse and a health economics and qualitative researcher, mobile fibroscan purchase and data collection (clinical, qualitative, patient reported 
and health economic outcomes). The Fibroscan (Figure 2) is a non-invasive painless liver scan that utilises liver stiffness as a measurement of severity of liver fibrosis (Sandrin et al., 2003). It is now a validated technique (sensitivity and specificity $70 \sim 90 \%$ ) for detection of all stages of liver fibrosis in individuals with most aetiologies of chronic liver disease including HCV (Sandrin et al., 2003; Talwalkar, 2007).

\section{Stage 3: Service set up}

This involved training of the hepatitis nurse (M.O.S.), identification of a lead psychiatrist at the SMS (H.W.), and detailed discussions with managers at SMS to address logistic issues including clinic space. The service was publicised by the on-going engagement with stakeholders, M.O.S. engaging with SMS staff and use of posters. Figure 3 summarises the stages in setting up the community HCV service.

\section{Prerequisites for a successful HCV community service}

In our view the following were prerequisites for a successful HCV community service:

- An integrated and multidisciplinary approach with provision of all components of the service at one site, preferably a SMS.

- An experienced community hepatitis nurse additionally trained in substance misuse and

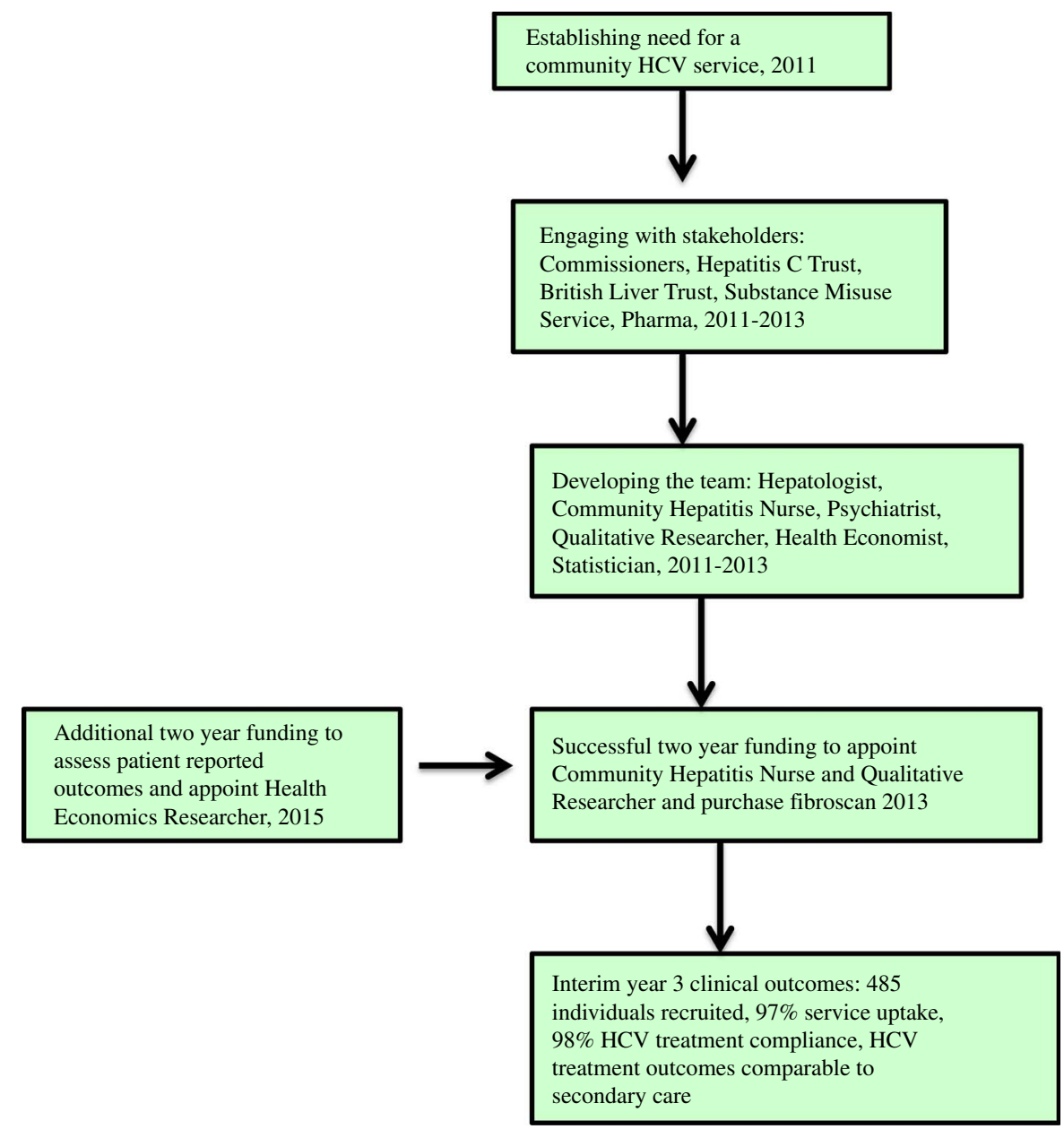

Figure 3 Stages in developing a community HCV service 
1. Testing for BBVs using DBST (dried blood spot testing), including confirmatory PCR for those who screen positive

2. Perform community based transient elastography for non-invasive assessment of hepatic fibrosis

3. Identify clients suitable for HCV treatment. Those with on going alcohol and substance misuse not excluded from treatment as long as willing to engage and stable housing.

4. Monitor HCV treatment under supervision of a Hepatologist.

5. Hepatitis $B$ virus vaccination for those not immune

6. Work closely with psychiatrist, peer advocates and key and social workers to ensure holistic care

Figure 4 Role of community hepatitis nurse

passionate about working with this client group to provide holistic care.

- Easy access to nurse (mobile phone) and close supervision by a hepatologist.

- Flexible clinic appointments in contrast to the inflexible, non-personalised and stigmatised environment in secondary care.

- Community Fibroscan for non-invasive staging of hepatic fibrosis.

- Presence of onsite psychiatrist.

- On going alcohol and drug use not a bar to HCV treatment.

- Personalised strategies for drug delivery (eg, home delivery).

- Provision of peer advocates (buddies) to support clients throughout their treatment journey.

- Good engagement between key workers, drug and alcohol team, psychiatrist, peer advocates and hepatitis nurse.

- Non-judgemental approach.

The role of the hepatitis nurse is summarised in Figure 4 and participant pathway in Figure 5.

\section{Delivery logistics and barriers to success}

Though the need for a community service was greatly appreciated, set up was associated with a variety of issues that included:

- Scepticism 'it ain't going to work'.

- Concerns about treating those with on-going drug and alcohol use 'can't be trusted with expensive drugs'.

- Misconceptions about treatment efficacy and reinfection risks in PWID.

- Logistic issues especially lack of clinical space. A change in providers in 2015 (Surrey and Borders) meant relocating the service to new premises. This heightened the issues of availability of clinical rooms. The SMS have now agreed to install an additional clinical room, that has been been part funded by the research grant.

- Concerns that interactions between the community hepatitis nurse, psychiatrist and key workers would be incongruent.

- Remote access to hospital pathology and radiology database - this was resolved with the use of a laptop and remote modem.

- On-going need to train the staff at the SMS in BBV testing and providing them with the latest HCV treatment updates. This required training of the substance misuse teams volunteers, peer mentors, those running narcotics/alcohol anonymous meetings, homeless hostel workers, rehabilitation units staff and GPs. In the past PWID would have been denied HCV treatment and so it is essential to dispel this antiquated myth amongst the medical and the wider community.

- Restrictive access to DAA due to prohibitive costs. The Early Access Programme enabled treatment of those with decompensated cirrhosis (Interim Clinical Commissioning Policy Statement, 2014). NHS England then extended treatment to cirrhotics (Clinical Commissioning Policy Statement, 2015) and subsequently to those with advanced fibrosis (LSM $>9.5 \mathrm{kPa}$ ). There are however exceptional criteria to include those with extra hepatic disease and PWID (as window of opportunity). Treatment can only be dispensed through nationally selected Operator Delivery Networks (ODNs) $(n=22)$, of which we are one. Each patient is discussed at a weekly multidisciplinary meeting. Each genotype has a first choice regimen and all second choice drugs (which in fact maybe more appropriate) need 'buddy ODN' approval. There are severe financial penalties for the ODN if guidelines are breached. Each ODN has been provided with a run rate based on the regional prevalence of $\mathrm{HCV}$ and again, there are financial penalties for exceeding this. While each ODN can treat a subset of patients (10-20\%) under the exceptional criteria, this remains highly scrutinised. It is therefore frustrating that despite effective antivirals and engaged SMS clients who often only have a small window of opportunity; we are still unable to offer treatment to a substantial number of PWID. This is in sharp contrast to countries like Australia where there is unrestricted access to DAA (including for reinfection) 


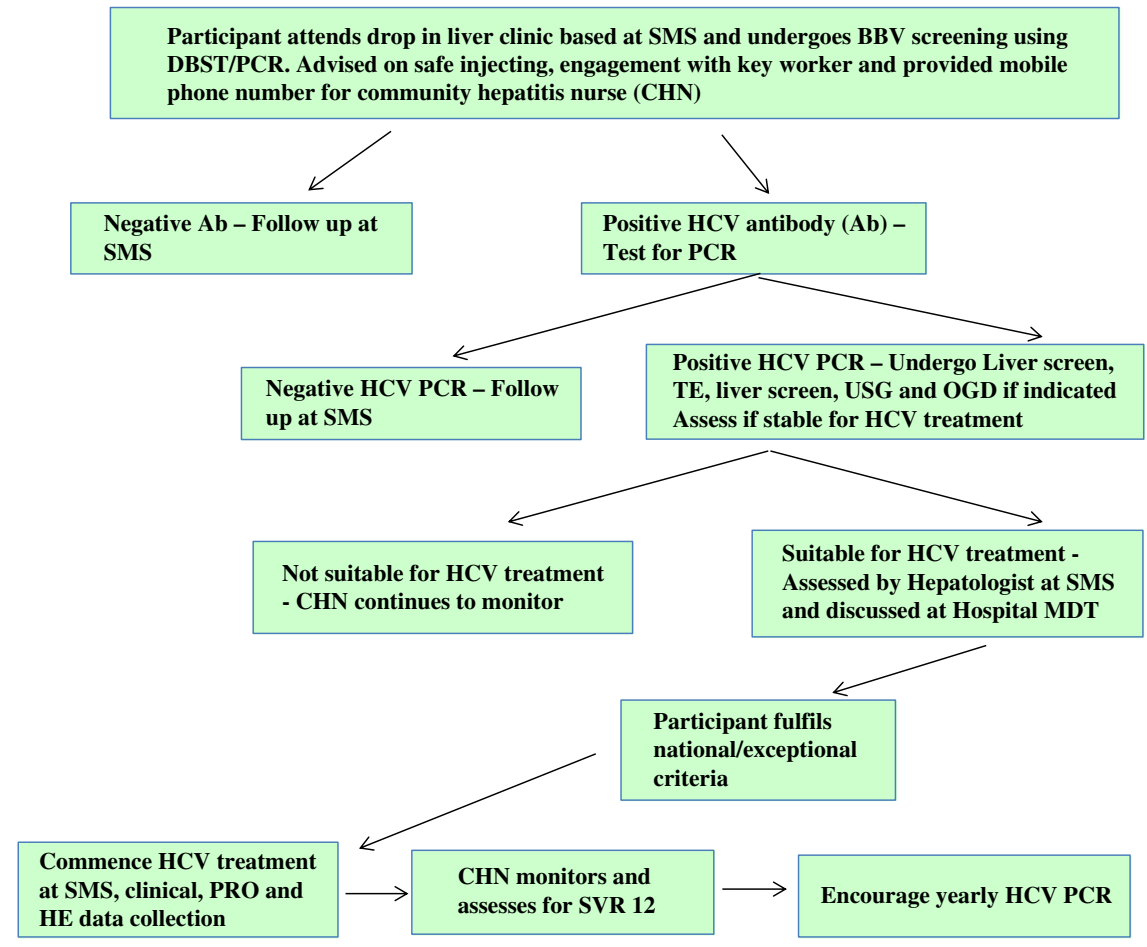

Peer advocates (buddy) support participants throughout their journey

Figure 5 Project ITTREAT: participant pathway. SMS=substance misuse service; BBV=blood borne viruses; DBST=direct blood spot testing; $P C R=$ polymerase chain reaction; $T E=$ transient elastography; USG=ultrasound; OGD=oesophagogastroduodenoscopy; $\mathrm{PRO}=$ patient reported outcomes; $\mathrm{HE}=$ health economics; SVR=sustained virological response.

and primary care physicians are encouraged to take on prescribing and treatment as already stated (Kirby Institute, 2016).

- Need for upfront funding for service set up - this has somewhat been negated by establishment of ODN and availability of CQUIN funds.

\section{Evaluating the service}

We aimed to evaluate this community-based HCV service through collection of following data:

1. Clinical: demographics, drug and alcohol use, uptake of DBST, HBV vaccination and $\mathrm{HCV}$ treatment as well as treatment outcomes.

2. Qualitative: Conduct of interviews with SMS attendees and two focus groups with staff members.

3. Patient reported outcomes using validated questionnaires

Primary Health Care Research \& Development 2018; 19: 110-120 a. Liver-related quality of life (QOL) - short-form liver disease quality of life (SF-LDQOL) (Gralnek et al., 2000; Kanwal et al., 2008).

b. Non-disease specific health-related outcomes SF-12v2, which is a shortened form (12 items) of the SF-36v2 Health Survey (SF-36).

4. Assessment of quality adjusted life years using EQ-5D-5L (EQ-5D-5L Survey) and perform a health economics assessment (cost per cure)

\section{Progress}

As already stated, detailed outcome data will not be presented in this manuscript. Our Year 3 interim clinical outcomes have been presented at the American Association for Study of Liver Disease meeting (2017) and are summarised below.

- To date, 485 individuals have been recruited, $80 \%(n=388)$ males, mean age $41.0+9.9$ years. 
- Prevalence of injecting drug use (IDU) [336 $(69 \%)]$, alcohol use [416 (86\%)] and psychiatric illness [225 (47\%)] remains high.

- Uptake of DBST was 97\% $(n=472)$. Prevalence of positive serological markers/PCR were: $\mathrm{HBcAb} 20 \% \quad(n=88), \mathrm{HCV}$ antibody $56 \%$ $(n=262)$ and HCV PCR $81 \%(211 / 262)$; genotypes $1=92(44 \%)$ and $3=94(44 \%)$.

- Independent predictors of a positive $\mathrm{HCV}$ serology were age, if ever injected, positive $\mathrm{HBcAb}$ and if ever had a psychiatric diagnosis $(P$-value for all $\leqslant 0.003)$.

- Of those with a positive HCV PCR $(n=211), 169$ $(80 \%)$ underwent transient elastography (TE) [median liver stiffness measurement (LSM) $6.8 \mathrm{kPa}(2.7-75], 76(45 \%)$ having significant fibrosis $(\mathrm{LSM} \geqslant 7.5 \mathrm{kPa}$, with 42 (25\%) having cirrhosis.

- A total of $66(31 \%)$ individuals were not treatment candidates (chaotic lifestyle), 87/145 $(60 \%)$ of the remaining with a positive PCR commencing HCV treatment in the community.

- Characteristics of treated cohort were: age $46 \pm 9.2$ years; $84 \%$ male; $29 \%$ and $20 \%$ having on-going alcohol and IDU, respectively; 95\% undergoing TE [median LSM $8.7 \mathrm{kPa}(2.7-75)$, $39 \%$ (34) having cirrhosis including four with decompensation]. Genotypes $1=48 \%, 3=45 \%$. Treatment received: pegylated interferon + ribavirin $18 \%$, pegylated interferon + DAA $19 \%$ and DAA $62 \%$. Of the 79 SVR results available, 69 (87\%) have achieved SVR.

- Compliance with treatment was $98 \%$.

- No reinfection till date (O’Sullivan et al., 2017).

Project ITTREAT has also been presented at earlier national and international conferences (O’Sullivan et al., 2015; 2016a; 2016b) and was selected by PHE as a showcase for good clinical practice (HCV Action and PHE Hepatitis C Roadshow, 2015). We are also exploring extension of the community hepatitis nurse role to include management of individuals with other forms of chronic liver disease including those with cirrhosis.

There is limited published evidence on community based integrated HCV treatment models in England. Without scientific evidence it will be challenging for local commissioners to develop effective local commissioning business cases. With this conundrum in mind we have drafted a successful business case for a community based integrated model of care. This has ensured the permanency of the community hepatitis nurse once research funding runs out in December 2017.

Based upon the success of Project ITTREAT our team has now established the Vulnerable Adult LIver Disease (VALID) project. This is a similar integrated community liver service based at two homeless hostels and offers non-invasive assessment of hepatic fibrosis (Fibroscan) followed by targeted treatment for chronic liver disease including for BBV (Hashim et al., 2017). NHS England have selected the VALID study for inclusion on a website which is a showcase for good practice (Learning Environment - NHS England, 2016).

\section{Conclusions and the future}

Linking PWIDs into care is essential if $\mathrm{HCV}$ infection is to be eliminated by 2030 as set out in the WHO strategy. These individuals have, however, consistently failed to access traditional models of secondary care. The advent of DAA provides an unprecedented opportunity to address the national HCV burden. Our integrated and multidisciplinary community models of care (Project ITTREAT, VALID Study) have been successful in engaging such individuals with outcomes comparable with secondary care, despite the complex nature of the cohort. Provision of all aspects of the care at one site, a dedicated and highly motivated team and the excellent communication between them and substance misuse staff, other community services, and stakeholders is the key to the success of this service. Our easy to replicate community HCV models have the potential for national adoption as does our business case for such a model.

\section{Acknowledgements}

We are grateful to the staff at the substance misuse service and homeless hostels for their invaluable support and contribution. Finally we are indebted to our patients who despite personal adversity engaged with our services.

\section{Financial Support}

This work has been supported by an educational grant from the Brighton and Hove Commissioner and Gilead Sciences (National Gilead Fellowship

Primary Health Care Research \& Development 2018; 19: 110-120 
and Gilead Investigator Sponsored Research Study IN-UK-337-1981). The funders were not involved in the study design and or selection of study outcome measures. Ethical approval was obtained (REC ref no 13/EM/0275).

\section{Conflicts of Interest}

S.V.: Research and educational grants/Honorarium from Brighton and Hove Commissioners, Gilead, Dunhill Medical Trust, the National Institute for Health Research and Kent Surrey and Sussex Deanery; Travel grants from B.M.S., Janssen, Abbvie, Gilead; M.O.S.:Travel grants from Gilead; A.H., H.W.: none.

\section{References}

Arora, S., Kalishman, S., Thornton, K., Dion, D., Murata, G., Deming, P., Parish, B., Brown, J., Komaromy, M., Colleran, K., Bankhurst, A., Katzman, J., Harkins, M., Curet, L., Cosgrove, E. and Pak, W. 2010: Expanding access to hepatitis $\mathrm{C}$ virus treatment-Extension for Community Healthcare Outcomes (ECHO) project: Disruptive innovation in specialty care. Hepatology, 52, 1124-33.

Bell, A., Wagner, J., Barber, K. and Stover, K. 2016: Elbasvir/ Grazoprevir: a review of the latest agent in the fight against hepatitis C. International Journal of Hepatology 2016, 1-8.

Beste, L., Glorioso, T., Ho, P., Au, D., Kirsh, S., ToddStenberg, J., Chang, M., Dominitz, J., Barón, A. and Ross, D. 2016: Telemedicine Specialty Support Promotes Hepatitis C Treatment by Primary Care Providers in the Department of Veterans Affairs. The American Journal of Medicine.

Bonkovsky, H., Tice, A., Yapp, R., Bodenheimer, H. Jr., Monto, A., Rossi, S. and Sulkowski, M. 2008: Efficacy and safety of peginterferon alfa-2a/ribavirin in methadone maintenance patients: randomized comparison of direct observed therapy and self-administration. The American Journal of Gastroenterology 103, 2757-765.

Bruggmann, P. and Litwin, A. 2013: Models of care for the management of hepatitis $\mathrm{C}$ virus among people who inject drugs: one size does not fit all. Clinical Infectious Diseases 57 (Suppl 2), S56-61.

Clinical Commissioning Policy Statement. 2015: NHS England: treatment of chronic hepatitis $\mathrm{C}$ in patients with cirrhosis. NHS England B07/P/a. Retrieved 13 March 2017 from https:// www.england.nhs.uk/commissioning/wp-content/uploads/ sites/12/2015/06/hep-c-cirrhosis-polcy-statmnt-0615.pdf.

Dillon, J.F., Lazarus, J.V. and Razavi, H.A. 2016: Urgent action to fight hepatitis $\mathrm{C}$ in people who inject drugs. Hepatology, Medicine and Policy 1, 1-10.

Dimova, R., Zeremski, M., Jacobson, I., Hagan, H., Des Jarlais, D. and Talal, A. 2012: Determinants of hepatitis C virus treatment

Primary Health Care Research \& Development 2018; 19: 110-120 completion and efficacy in drug users assessed by metaanalysis. Clinical Infectious Diseases 56, 806-16.

Dore, G., Altice, F., Litwin, A., Dalgard, O., Gane, E., Shibolet, O., Luetkemeyer, A., Nahass, R., Peng, C., Conway, B., Grebely, J., Howe, A., Gendrano, I., Chen, E., Huang, H., Dutko, F., Nickle, D., Nguyen, B., Wahl, J., Barr, E., Robertson, M. and Platt, H. 2016: Elbasvir-Grazoprevir to treat hepatitis $\mathrm{C}$ virus infection in persons receiving opioid agonist therapy. Annals of Internal Medicine, 625-34.

EQ-5D-5L Survey. Retrieved 15 February 2017 from http:// www.euroqol.org/fileadmin/user_upload/Documenten/ PDF/Folders_Flyers/EQ-5D-5L_UserGuide_2015.pdf.

Feld, J., Jacobson, I.M., Hezode, C., Asselah, T., Ruane, P.J., Gruener, N., Abergel, A., Mangia, A., Lai, C.L., Chan, H.L., Mazzotta, F., Moreno, C., Yoshida, E., Shafran, S.D., Towner, W.J., Tran, T.T., McNally, J., Osinusi, A., Svarovskaia, E., Zhu, Y., Brainard, D.M., McHutchison, J.G., Agarwal, K. and Zeuzem, S; ASTRAL-1 Investigators 2015: Sofosbuvir and velpatasvir for HCV genotype 1, 2, 4, 5, and 6 infection. New England Journal of Medicine 373, 2599-607.

Feld, J., Kowdley, K., Coakley, E., Sigal, S., Nelson, D., Crawford, D., Weiland, O., Aguilar, H., Xiong, J., PilotMatias, T., DaSilva-Tillmann, B., Larsen, L., Podsadecki, T. and Bernstein, B. 2014: Treatment of HCV with ABT-450/ r-Ombitasvir and Dasabuvir with Ribavirin. New England Journal of Medicine 370, 1594-603.

Global Burden of Disease and WHO/UNAIDS Estimates. 2015: Retrieved 15 February 2017 from http://ihmeuw.org/ 3 pmt.

Gralnek, I.M., Hays, R.D., Kilbourne, A., Rosen, H.R., Keeffe, E.B., Artinian, L., Kim, S., Lazarovici, D., Jensen, D. M., Busuttil, R.W. and Martin, P. 2000: Development and evaluation of the liver disease quality of life instrument in persons with advanced, chronic liver disease - the LDQOL 1.0. The American Journal of Gastroenterology 95, 3552-565.

Grebely, J., Alavi, M., Micallef, M., Dunlop, A., Balcomb, A., Phung, N., Weltman, M., Day, C., Treloar, C., Bath, N., Haber, P. and Dore, G. 2016: Treatment for hepatitis C virus infection among people who inject drugs attending opioid substitution treatment and community health clinics: the ETHOS Study. Addiction 111, 311-19.

Harris, R., Martin, N., Rand, E., Mandal, S., Mutimer, D., Vickerman, P., Ramsay, ME., De Angilis, D., Hickman, M. and Harris, H.E. 2016: New treatments for hepatitis $\mathrm{C}$ virus (HCV): scope for preventing liver disease and $\mathrm{HCV}$ transmission in England. Journal of Viral Hepatitis 8, 631-43.

Harris, R., Ramsay, M., Hope, V., Brant, L., Hickman, M., Foster, G. and De Angelis, D. 2012: Hepatitis C prevalence in England remains low and varies by ethnicity: an updated evidence synthesis. The European Journal of Public Health 22, 187-92.

Hashim, A., Worthley, T., Bremner, S., Macken, L., Aithal, G. and Verma, S. 2017: A dedicated hostel-based community liver service for Homeless and Vulnerable Adults: VALID (Vulnerable Adults LIver Disease) Study. Hepatology 66 (Suppl 1), 318A. 
HCV Action \& PHE Hepatitis C Roadshow in Brighton. 2015: Retrieved 15 February 2017 from http://www.hcvaction.org. uk/resource/hcv-action-phe-hepatitis-c-roadshow-brightonpresentations.

HCV in England. 2017: Headline data table. Retrieved 25 March 2017 from: https://www.gov.uk/government/publica tions/hepatitis-c-in-the-uk.

Howes, N., Lattimore, S., Irving, W.L. and Thomson, B.J. 2016: Clinical care pathways for patients with hepatitis C: reducing critical barriers to effective treatment. Open Forum Infectious Diseases 3, ofv218.

Interim Clinical Commissioning Policy Statement. 2014: Sofosbuvir + Daclatasvir/Ledipasvir + /-Ribivirin for defined patients with hepatitis C. NHS England A02/PS/b. Retrieved 25 March 2017 from https://www.england.nhs. uk/wp-content/uploads/2014/04/sofosbuvir-pol-stat.pdf.

Irving, W.L., Smith, S., Cater, R., Pugh, S., Neal, K.R., Coupland, C.A., Ryder, S.D., Thomson, B.J., Pringle, M., Bicknell, M. and Hippisley-Cox, J. 2006: Clinical pathways for patients with newly diagnosed hepatitis $\mathrm{C}$ - what actually happens. Journal of Viral Hepat.itis 13, 264-71.

Jack, K., Willott, S., Manners, J., Varnam, M. and Thomson, B. 2009: Clinical trial: a primary-care-based model for the delivery of anti-viral treatment to injecting drug users infected with hepatitis C. Alimentary Pharmacology \& Therapeutics 29, 38-45.

Kanwal, F., Spiegel, B., Hays, R., Durazo, F., Han, S., Saab, S., Bolus, R., Kim, S. and Gralnek, I. 2008: Prospective validation of the short form liver disease quality of life instrument. Alimentary Pharmacology \& Therapeutics 28, 1088-101.

The Kirby Institute. 2016: Monitoring hepatitis C treatment uptake in Australia (Issue 3). The Kirby Institute, UNSW, Sydney, Australia. Retrieved 13 March 2017 from http:// kirby.unsw.edu.au/research-programs/vhcrp-newsletters.

Kowdley, K., Gordon, S., Reddy, K., Rossaro, L., Bernstein, D., An, D., Svarovskaia, E., Hyland, R., Pang, P., Symonds, W., McHutchison, J., Muir, A., Pockros, P., Pound, D. and Fried, M. 2014: 764 Sofosbuvir/Ledipasvir with and without Ribavirin for 8 weeks compared to Sofosbuvir/Ledipasvir for 12 weeks in treatment-naive non-cirrhotic genotype-1 $\mathrm{HCV}$-infected patients: the phase 3 ion-3 study. Gastroenterology 146, S-926.

Learning Environment - NHS England. 2016: Retrieved 15 February 2017 from https://learnenv.england.nhs.uk/ pinboard/view/352.

Lewis, H., Kunkel, J., Axten, D., Dalton, J., Gardner, H., Tippett, A., Wynne, S., Wilkinson, M. and Foster, G. 2016: Community nurse-led initiation of antiviral therapy for chronic hepatitis $\mathrm{C}$ in people who inject drugs does not increase uptake of or adherence to treatment. European Journal of Gastroenterology \& Hepatology 28, 1258-263.

Martin, N., Vickerman, P., Dore, G., Grebely, J., Miners, A., Cairns, J., Foster, G., Hutchinson, S., Goldberg, D., Martin, T., Ramsay, M. and Hickman, M. 2016: Prioritization of HCV treatment in the direct-acting antiviral era: an economic evaluation. Journal of Hepatology $65,17-25$.

Martin, N.K., Vickerman, P., Grebely, J., Hellard, M., Hutchinson, S.J., Lima, V.D., Foster, G.R., Dillon, J.F., Goldberg, D.J., Dore, G.J. and Hickman, M. 2013: Hepatitis $\mathrm{C}$ virus treatment for prevention among people who inject drugs: modelling treatment scale-up in the age of directacting antivirals. Hepatology 58, 1598-609.

Marufu, M., Williams, H., Hill, S., Tibble, J. and Verma, S. 2012: Gender differences in hepatitis $\mathrm{C}$ seroprevalence and suboptimal vaccination and hepatology services uptake amongst substance misusers. Journal of Medical Virology 84, 1737-743.

Mehta, S., Genberg, B., Astemborski, J., Kavasery, R., Kirk, G., Vlahov, D., Strathdee, S. and Thomas, D. 2008: Limited uptake of hepatitis $\mathrm{C}$ treatment among injection drug users. Journal of Community Health 33, 126-33.

O'Sullivan, M., Williams, H., Jones, A. and Verma, S. 2015: P0722: Non-invasive detection, stratification and treatment of chronic hepatic $\mathrm{C}$ related liver disease amongst substance users in the community: a prospective study. Journal of Hepatology 62 (Suppl 2), S595.

O'Sullivan, M., Williams, H., Jones, A. and Verma, S. 2016a: Project ITTREAT (integrated community based test-stageTREAT) HCV service for people who inject drugs (PWID). Hepatology, 64 (Suppl 1), Abstract 781.

O'Sullivan, M., Williams, H., Jones, A. and Verma, S. 2016b: Project ITTREAT (integrated community based test-stageTREAT) HCV service for people who inject drugs (PWID). British Association for Study of Liver, Abstract 635.

O'Sullivan, M., Williams, H., Jones, A. and Verma, S. 2017: Project ITTREAT (integrated community based test stage-TREAT HCV service) for people who inject drugs: year 3 results. Hepatology 66 (Suppl 1), 532A.

PHE fingertips. Liver disease profiles. Retrieved 15 February 2017: from https://fingertips.phe.org.uk/profile/liver-disease/ data\#page/0.

Public Health England (PHE). 2017a: HCV in England 2017 Headline Data Table 2017. Retrieved 25 March 2017 from https://www.gov.uk/government/publications/hepatitis-c-inthe-uk.

Public Health England (PHE). 2017b: HCV in England 2017 Headline Data Table. 2017. Retrieved 15 March 2017 from https://www.gov.uk/government/publications/hepatitis-c-inthe-uk.

Public Health England (PHE). 2017c: Hepatitis C in England 2017 report. Retrieved 15 March 2017 from https://www. gov.uk/government/publications/hepatitis-c-in-the-uk.

Remy, A.J., Bouchkira, H., Lamarre, P. and Montabone, S. 2016: Hepatitis Mobile Team: a new concept for benefit toward drugs users and precarious people with hepatitis $\mathrm{C}$ in France. Hepatology 64 (Suppl 1), Abstract no. 775.

Rich, R.C., Chu, C., Mao, J., Zhou, K., Cai, W., Ma, Q., Volberding, P. and Tucker, J.D. 2016: Facilitators of HCV treatment adherence among people who inject drugs: a systematic qualitative review and implications for scale up of direct acting antivirals. BMC Public Health 16, 1-10. 
Roberts, K., Macleod, J., Metcalfe, C., Simon, J., Horwood, J., Hollingworth, W., Marlowe, S., Gordon, F., Muir, P., Coleman, B., Vickerman, P., Harrison, G., Waldron, C., Irving, W. and Hickman, M. 2016: Hepatitis C-assessment to treatment trial (HepCATT) in primary care: study protocol for a cluster randomised controlled trial. Trials $17,1-8$.

Sandrin, L., Fourquet, B., Hasquenoph, J., Yon, S., Fournier, C., Mal, F., Christidis, C., Ziol, M., Poulet, B., Kazemi, F., Beaugrand, M. and Palau, R. 2003: Transient elastography: a new noninvasive method for assessment of hepatic fibrosis. Ultrasound in Medicine \& Biology 29, $1705-713$.

Seidenberg, A., Rosemann, T. and Senn, O. 2013: Patients receiving opioid maintenance treatment in primary care: successful chronic hepatitis $\mathrm{C}$ care in a real world setting. BMC Infectious Diseases 13, 1-7.

Selvapatt, N., Ward, T., Harrison, L., Lombardini, J., Thursz, M., McEwan, P. and Brown, A. 2016: The cost impact of outreach testing and treatment for hepatitis $\mathrm{C}$ in an urban drug treatment unit. Liver International 37, 345-53.

SF-36 questionnaire. Retrieved 15 February 2017 from http://www.sf-36.org/tools/sf12.shtml.

Sylvestre, D. and Clements, B. 2007: Adherence to hepatitis C treatment in recovering heroin users maintained on methadone. European Journal of Gastroenterology \& Hepatology 19, 741-47.

Talwalkar, J.A., Kurtz, D.M., Schoenleber, S.J., West, C.P., Montori, V.M. 2007: Ultrasound-based transient elastography for the detection of hepatic fibrosis: systematic review and meta-analysis. Clinical Gastroneterology and Hepatology 5, 1214-20.
UK Transplant Registry. NHS Blood and Transplant. 2017: Retrieved 25 March 2017 from http://www.odt.nhs.uk/uktransplant-registry/.

Unlinked Anonymous Monitoring Survey (UAMS). 2017: People Who Inject Drugs: HIV and viral hepatitis monitoring. Retrieved 15 March 2017 from www.gov.uk/ government/publications/people-who-inject-drugs-hiv-andviral-hepatitis-monitoring.

Wedemeyer, H., Duberg, M., Buti, W., et al. 2014: Strategies to manage hepatitis $\mathrm{C}$ virus (HCV) disease burden. Journal of Viral Hepatitis 21 (Suppl 1), 60-89.

Wilkinson, M., Crawford, V., Tippet, A., Jolly, F., Turton, J., Sims, E., Hekker, M., Dalton, J., Marley, R. and Foster, G. 2009: Community-based treatment for chronic hepatitis $\mathrm{C}$ in drug users: high rates of compliance with therapy despite ongoing drug use. Alimentary Pharmacology \& Therapeutics 29, 29-37.

Williams, R., Aspinall, R., Bellis, M., Camps-Walsh, G., Cramp, M., Dhawan, A., Ferguson, J., Forton, D., Foster, G., Gilmore, S.I., Hickman, M., Hudson, M., Kelly, D., Langford, A., Lombard, M., Longworth, L., Martin, N., Moriarty, K., Newsome, P., O'Grady, J., Pryke, R., Rutter, H, Ryder, S., Sheron, N. and Smith, T. 2014: Addressing liver disease in the UK: a blueprint for attaining excellence in health care and reducing premature mortality from lifestyle issues of excess consumption of alcohol, obesity, and viral hepatitis. Lancet 6736, 61838-1839.

World Health Organization. 2016-2021: Draft global health sector strategy on viral hepatitis, Retrieved 15 February 2017 from http://www.who.int/hepatitis/strategy2016-2021/ Draft_global_health_sector_strategy_viral_hepatitis_13nov. pdf?ua=1. 